\title{
Correction to: Acute disseminated encephalomyelitis-like presentation after an inactivated coronavirus vaccine
}

\author{
Gulay Ozgen Kenangil ${ }^{1} \cdot$ Buse Cagla Ari ${ }^{1}\left[\right.$ Cagan Guler ${ }^{1} \cdot$ Mustafa Kemal Demir $^{2}$
}

C Belgian Neurological Society 2022

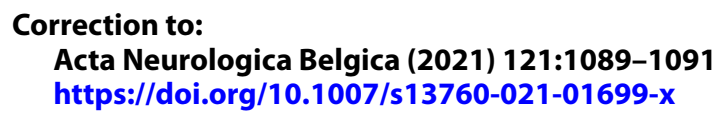

Contrary to the previous clinical reasoning about a possible relationship or the patient's status with vaccination, the final histopathological diagnosis of the case reported in "Acute disseminated encephalomyelitis-like presentation after an inactivated coronavirus vaccine" was a high grade glioma proven by the biopsy, which was unrelated to the vaccine. The authors apologize for any misunderstanding.

Publisher's Note Springer Nature remains neutral with regard to jurisdictional claims in published maps and institutional affiliations.

The original article can be found online at https://doi.org/10.1007/ s13760-021-01699-x.

Buse Cagla Ari

juvelia@gmail.com

1 Department of Neurology, Bahcesehir University Faculty of Medicine, Istanbul, Turkey

2 Department of Radiology, Bahcesehir University Faculty of Medicine, Istanbul, Turkey 